\title{
BMP7 regulates lung fibroblast proliferation in newborn rats with bronchopulmonary dysplasia
}

\author{
YANLI SUN, JIANHUA FU, XINDONG XUE, HAIPING YANG and LINLIN WU \\ Department of Pediatrics, Shengjing Hospital of China Medical University, Shenyang, Liaoning 110004, P.R. China
}

Received March 5, 2017; Accepted October 3, 2017

DOI: $10.3892 / \mathrm{mmr} .2018 .8692$

\begin{abstract}
The present study investigated the expression of bone morphogenetic protein (BMP) 7 in a newborn rat model of bronchopulmonary dysplasia (BPD) and the biological effects of BMP7 on newborn rat lung fibroblast (LF) cells. For this purpose, a total of 196 newborn rats were randomly and equally assigned to a model group and a control group. Lung tissue was collected at days 3, 7, 14 and 21 for histological analysis. The location and expression of BMP7 was examined by immunohistochemical staining and reverse transcription-quantitative polymerase chain reaction (RT-qPCR) analysis. A total of 38 full-term newborn rats on the day of birth were sacrificed and LF cells were isolated and treated with BMP7. The biological effects of BMP7 on LF cells were assessed by cell proliferation and cell cycle analysis. The findings demonstrated that abnormal alveolar development due to BPD was gradually intensified in the model group over time. Immunohistochemical staining revealed that the location of BMP7 in lung tissue was altered. Immunohistochemistry and RT-qPCR assays demonstrated a gradual decrease in BMP7 expression in the model group induced by hyperoxia. MTT assays demonstrated that BMP7 inhibited LF cells and the inhibitory effect was dose-dependent and time-dependent. Flow cytometry revealed that the inhibitory effect of BMP7 in LF cells was causing cell cycle arrest at the $G_{1}$ phase. The present study demonstrated that BMP7 may serve an important role in alveolar development in a BPD model. BMP7 may be involved in abnormal alveolar development through the regulation of LF proliferation.
\end{abstract}

Correspondence to: Professor Jianhua Fu, Department of Pediatrics, Shengjing Hospital of China Medical University, 36 Sanhao Street, Shenyang, Liaoning 110004, P.R. China E-mail: jianhuafu1965@126.com

Key words: bone morphogenetic protein 7, proliferation, lung fibroblasts, lung development, bronchopulmonary dysplasia

\section{Introduction}

Bronchopulmonary dysplasia (BPD) is one of the most serious complications in premature infants and remains a substantial lifelong burden. In recent years, as significant advances in respiratory care have been made in neonatal medicine, the survival rates of premature infants have increased; however, it appears that the incidence of BDP is stagnant, or even increasing $(1,2)$. Eunice Kennedy Shriver National Institute of Child Health and Human Development Neonatal Network Data reveal that the morbidity of BPD is $68 \%$ during the premature births with a birth weight of 401-1,500 $\mathrm{g}$ (3). The pathogenesis of BPD is unclear and there are no safe and effective preventative therapies $(4,5)$. Therefore, novel treatment strategies are required for the prevention of BPD and it remains important to explore the pathogenesis and clinical treatment of BPD.

Infants with severe BPD exhibit abnormal alveolar and vascular development $(6,7)$, and a hyperoxia-induced model is frequently used to study BPD. In this model, the principal pathological changes are alveolar simplification, abnormal vascularization and varying degrees of pulmonary fibrosis (8). Numerous growth factors are involved in abnormal alveolar development, and the most important is transforming growth factor- $\beta$ (TGF- $\beta$ ). Overexpression of TGF- $\beta$ is involved in BPD via the inhibition of alveolar development and the induction of lung fibroblast (LF) proliferation (9). The function of bone morphogenetic protein (BMP) 7 in BPD is, however, largely unknown. Therefore, to investigate the effect of BMP7 on pathological changes in the lungs of BPD is crucial. It is important to identify improved methods of protection against, and clinical treatment of, BPD.

BMP7 is a member of the TGF- $\beta$ superfamily of growth factors and possesses various biological functions (10-12). BMP7 appears to inhibit the effects of TGF- $\beta$-induced fibrogenesis as a natural antagonist (13). BMP7 counteracts TGF- $\beta$ activity during ongoing fibrogenesis in various organs, including the liver, lungs and kidneys (14-19). Previous research has demonstrated that BMP7 inhibits the development of fibrosis in thioacetamide-treated rat liver and that therapeutic application of recombinant human BMP7 or functionally active BMP7 fragments may be advantageous for experimental fibrosis in rats $(20,21)$. A lack of BMP7 may lead to extracellular matrix protein accumulation in the mesangial area, and BMP7 serves an important function in regulating glomerular structural homeostasis (22). Downregulation 
of BMP7 expression improves renal fibrosis and accelerates the return of renal function in experimental models of renal disease $(18,23)$. Experimental results have confirmed that BMP7 may reduce asbestos-induced fibrotic alterations in the lung (19). BMP7 mRNA was persistently induced in didecyldimethylammonium chloride (DDAC)-induced pulmonary damage, suggesting that BMP7 is a negative regulator of fibrosis (24). An additional study suggested that BMP7 opposed the TGF- $\beta 1$-mediated fibrogenic activity of pulmonary myofibroblasts in culture (25).

However, the effect of BMP7 on LFs is insufficient and previous studies primarily focused on lung tissue and other organs of adult animals (19-23). The expression of BMP7 is unclear in neonatal rats with BPD. The primary aim of the present study was to examine the expression of BMP7 and the association between decreased expression of BMP7 and abnormal alveolar development. The present study additionally aimed to demonstrate that LF proliferation is inhibited by BMP7, which is the possible mechanism underlying abnormal alveolar development.

\section{Materials and methods}

Animal models. A total of 24 time-dated, pregnant Wistar rats (220-240 g) were purchased from the Center for Experimental Animals of China Medical University (Shenyang, China). All animal procedures were reviewed and approved by the Laboratory Animal Ethics Committee of China Medical University. All surgeries were performed under chloral hydrate anesthesia, and all efforts were made to minimize animal suffering. Pups were delivered naturally at term gestation (21 days). A total of 196 full-term newborn rats from 20 litters were randomly marked and assigned to two groups, and were exposed to hyperoxia (80-90\% oxygen; experimental group) or normoxia (21\%; control group) beginning on the day of birth. The inhaled oxygen concentration was measured and recorded continuously with an analyzer equipped with a strip-chart recorder (model 572; Servomex; Spectris plc, Egham, UK). Humidity was routinely set to $60-70 \%$. The temperature was $25-27^{\circ} \mathrm{C}$ with a light/dark cycle of $10 / 14 \mathrm{~h}$ and access to food and water ad libitum. Nursing rat dams were switched every $24 \mathrm{~h}$ between the hyperoxic and normoxic chambers, to avoid oxygen toxicity and to provide equal nutrition to each litter. Chambers were open for $30 \mathrm{~min} /$ day for cage cleaning. Pups were sacrificed and lungs were harvested at the end of $3,7,14$ and 21 days of exposure. The left lungs were fixed in $4 \%$ paraformaldehyde for hematoxylin and eosin staining (HE), and the right lungs were frozen at $-80^{\circ} \mathrm{C}$ for reverse transcription-quantitative polymerase chain reaction (RT-qPCR) analysis.

Lung histology. Pups were anesthetized with an intraperitoneal injection of $10 \%$ chloral hydrate $(300-500 \mathrm{mg} / \mathrm{kg})$ and sacrificed by cervical dislocation, and their chests were opened for the isolation of lung tissues. The left lungs were fixed in $4 \%$ paraformaldehyde for $24 \mathrm{~h}$ at room temperature. Lung tissue was dehydrated with graded alcohol, placed in xylene for $1 \mathrm{~h}$ and then embedded in paraffin at $60^{\circ} \mathrm{C}$. Sections of lung $(4 \mu \mathrm{m})$ were stained with $\mathrm{HE}$ at room temperature, with $10 \mathrm{~min}$ hematoxylin and $1 \mathrm{~min}$ eosin staining. Morphological alterations were assessed using an optical microscope (H600L; Nikon Corporation, Tokyo, Japan). From each section, 10 random areas were examined at x20 magnification. The radial alveolar count (RAC) was counted with a method developed by Emery and Mithal, as described in a previous study (26), to assess the level of alveolar development. The RAC of each section was evaluated by two independent pathologists who were blinded to the experimental design.

Immunohistochemical staining. Following fixation in $4 \%$ paraformaldehyde, the lung tissues were embedded in paraffin and sliced in $4-\mu \mathrm{m}$-thick sections. The sections were dewaxed, incubated in $3 \% \mathrm{H}_{2} \mathrm{O}_{2}$ for $15 \mathrm{~min}$ to eliminate endogenous peroxidase activity, and incubated in pancreatin (Gibco; Thermo Fisher Scientific, Inc., Waltham, MA, USA) for 15 min at room temperature. The sections were washed three times with PBS, blocked with rabbit serum (OriGene Technologies, Inc., Beijing, China) and incubated with a primary antibody targeting BMP7 (cat. no. ab56023; 1:125; Abcam, Cambridge, UK) overnight at $4^{\circ} \mathrm{C}$. The tissues were washed 3 times with $\mathrm{PBS}$, and processed following the protocols provided in the UltraSensitive serum amyloid $\mathrm{P}$ (goat) immunohistochemistry kit (OriGene Technologies, Inc., Beijing, China). Sections were developed using the peroxidase substrate diaminobenzidine detection kit (OriGene Technologies, Inc.) and were counterstained with hematoxylin for $30 \mathrm{sec}$ at room temperature. In control experiments, the primary antibody was replaced with PBS. Cells with brown particles deposited in their cytoplasm were counted as BMP7-positive cells. A total of 10 sections were selected at each time point for each group and 10 visual fields were selected from each section under a light microscope at x40 magnification (H600L; Nikon Corporation). The protein expression was semi-quantitatively detected using an image analysis system (Universal Imaging, Downingtown, PA, USA). The staining intensity was analyzed with MetaMorph software (version 5.0; Universal Imaging). The average optical density denoted the intensity of BMP7 protein expression.

$R T$-qPCR analysis. Total RNA was extracted from right lung lobes cells using TRIzol reagent (Invitrogen; Thermo Fisher Scientific, Inc.) and frozen at $-80^{\circ} \mathrm{C}$, according to the manufacturer's protocol (Takara Bio, Inc., Otsu, Japan). A total of $1 \mathrm{mg}$ RNA from each sample was reverse-transcribed into cDNA using SuperScript III (Invitrogen; Thermo Fisher Scientific, Inc.), according the manufacturer's protocol. qPCR was performed on a LightCycler (7500 FAST Real-Time PCR System; Applied Biosystems; Thermo Fisher Scientific, Inc.) using appropriate primers (synthesized by Takara Bio, Inc.): BMP7 sense, 5'-CAGCCACCAGCAACCACT-3' and antisense, 5'-GTCCATGCCGTCCAATCA-3'; standardized GAPDH (commodity label DR3783). The amplification reaction was performed as follows: 40 cycles of $95^{\circ} \mathrm{C}$ for $10 \mathrm{sec}$, $95^{\circ} \mathrm{C}$ for $5 \mathrm{sec}$ and $60^{\circ} \mathrm{C}$ for $20 \mathrm{sec}$; and $65^{\circ} \mathrm{C}$ for $15 \mathrm{sec}$. The relative level of mRNA expression was calculated following normalization with GAPDH (27). Experiments were repeated six times.

LF cell isolation and purification. A total of 38 full-term newborn rats from 4 litters on the day of birth were sacrificed and LFs were isolated by two steps of trypsin digestion, as 
previously described (28). A tracheal cannula was placed in the anesthetized rat for lung ventilation. Cold D-Hanks solution was used for lung lavage via cardiopulmonary perfusion to remove blood. The lung tissues were minced and dissociated with trypsin solution. Following enzymatic digestion, the residual trypsin was neutralized with the same volume of Dulbecco's modified Eagle's medium (DMEM; Beijing Solarbio Science \& Technology Co., Ltd., Beijing, China) containing 10\% fetal bovine serum (Clark Bioscience, Richmond, VA, USA). LFs were purified by filtration through nylon meshes and by centrifugation at $114 \mathrm{x} \mathrm{g}$ for $5 \mathrm{~min}$ at room temperature. Cells were seeded in $25 \mathrm{~cm}^{3}$ culture flasks at a density of $5 \times 10^{5}$ cells $/ 1$ and incubated at $37^{\circ} \mathrm{C}$ in $5 \% \mathrm{CO}_{2}$ with the DMEM changed each day. The cells were trypsinized and reseeded following $\sim 3$ days of culture for further purification. The third generation of LF cells were used for the MTT assay and flow cytometry (FCM).

MTT assay. The effect of BMP7 on cell proliferation was detected by MTT assay. The LF cells were seeded at a density of 10,000 cells/well in 96-well plates. Following $24 \mathrm{~h}$ of culture, the cells were treated with 0 (serum-free medium), 5, 10 and $50 \mathrm{ng} / \mathrm{ml} \mathrm{BMP7} \mathrm{for} \mathrm{12,} 24$ and $48 \mathrm{~h}$. Subsequently, $20 \mu \mathrm{l}$ MTT solution (5 mg/ml) was added to each well and incubated at $37^{\circ} \mathrm{C}$ for $4 \mathrm{~h}$. The medium was carefully aspirated and the purple formazan crystals were solubilized with $150 \mu 1$ dimethyl sulfoxide. Optical density was measured at $490 \mathrm{~nm}$ using a microplate reader (BioTek Instruments, Inc., Winooski, VT, USA). Experiments were repeated three times.

Cell cycle analysis. The effect of BMP7 on the cell cycle of LF cells was analyzed by FCM. The cells were seeded at a density of $1 \times 10^{6}$ cells $/ \mathrm{ml}$ in a $25-\mathrm{cm}^{3}$ culture flask, and treated with different concentrations of BMP7 $(0,5,10$ and $50 \mathrm{ng} / \mathrm{ml})$ for $12 \mathrm{~h}$, or treated with $50 \mathrm{ng} / \mathrm{ml} \mathrm{BMP-7}$ for different time points $(12,24$ and $48 \mathrm{~h}$ ). Cells were harvested and fixed in $70 \%$ ethanol at $4^{\circ} \mathrm{C}$ overnight. The fixed cells were centrifuged at $114 \mathrm{x} \mathrm{g}$ for $15 \mathrm{~min}$ at room temperature and washed with cold PBS three times. Then cells were incubated with $50 \mu \mathrm{g} / \mathrm{ml}$ RNase A at $37^{\circ} \mathrm{C}$ for $30 \mathrm{~min}$. Subsequently, cells were incubated with $100 \mu \mathrm{g} / \mathrm{ml}$ propidium iodide (PI) in the dark at $4^{\circ} \mathrm{C}$ for $30 \mathrm{~min}$. The DNA content of the cells was quantified by FCM (BD CellQuest Pro; Biosciences, Franklin Lakes, NJ, USA). Experiments were repeated six times.

Statistical analysis. SPSS software version 17.0 (SPSS, Inc., Chicago, IL, USA) was used for statistical analysis. Data are summarized as the mean \pm standard deviation. Student's t-test was used to determine the significant differences between two groups. One-way analysis of variance and the Bonferroni test was used to determine the significant differences among multiple groups. $\mathrm{P}<0.05$ was considered to indicate a statistically significant difference.

\section{Results}

Lung histology. Histological analysis of lung tissues was performed (Fig. 1). In the control group at day 3, the lung tissues from normal full-term newborn rats exhibited an

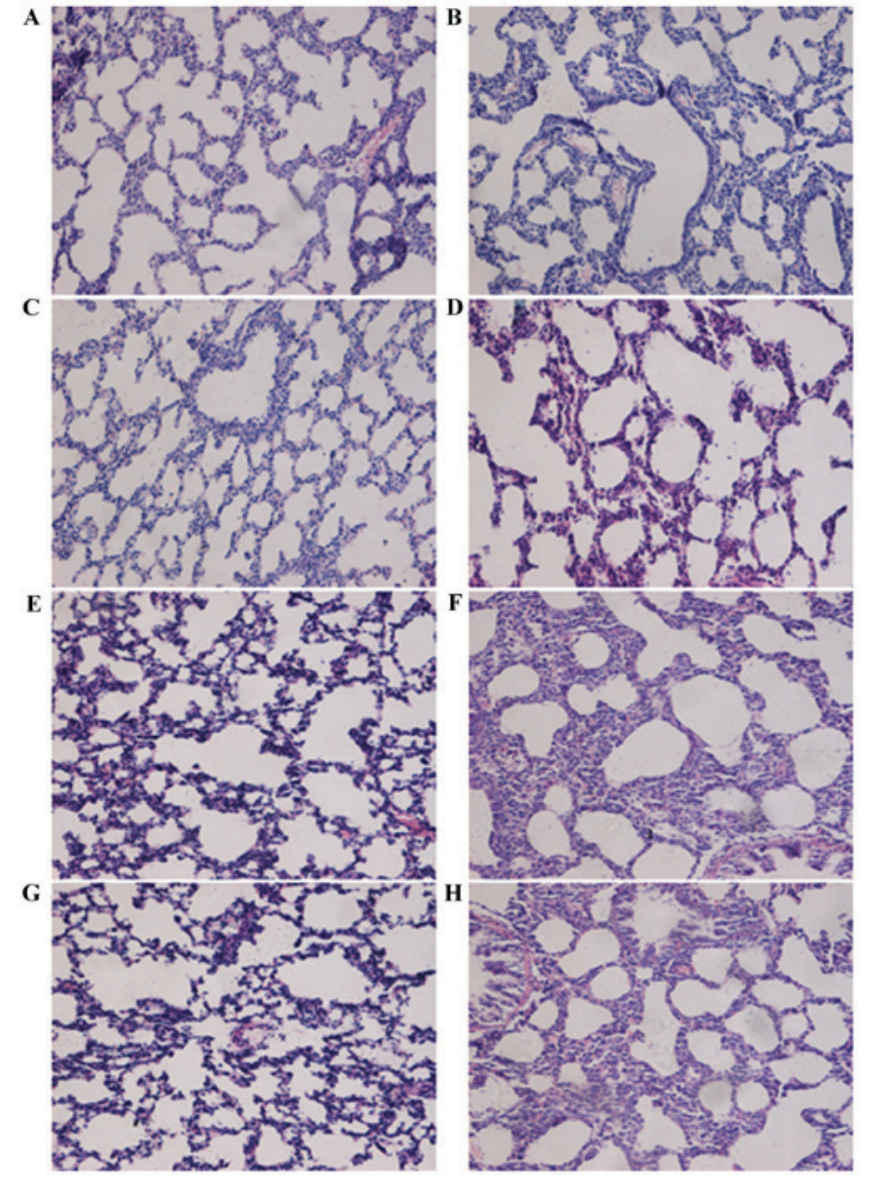

Figure 1. Lung histological alterations visualized with hematoxylin and eosin staining. Magnification, x20. (A) Examination of lung tissue morphology in the normoxia group (the control group) at day 3.(B) The pulmonary septa were thickened in the hyperoxia group (the model group) at day 3. (C) The alveoli were regular and uniformly distributed in newborn rats in the control group at day 7. (D) At day 7 of hyperoxic exposure, decreased alveoli, pulmonary secondary septa number and increased alveolar size were observed. (E) The pulmonary septa became thinner, the number of pulmonary secondary septa and alveoli increased in control group at day 14. (F) In the model group, the pulmonary septa were markedly thicker, and the number of secondary septa and alveoli was significantly decreased at day 14. (G) At day 21, more pulmonary secondary septa and alveoli were observed and the alveoli were distributed more regularly and uniformly in the control group. (H) At day 21, the difference became more marked compared with day 14 , and the normal structure of alveoli disappeared in the model group.

irregular alveolus-like structure and a number of pulmonary septa (Fig. 1A); at day 7, pulmonary septa were thinner and the number of pulmonary alveoli increased (Fig. 1C); at day 14, pulmonary septa became even thinner and the number of pulmonary secondary septa and alveoli increased (Fig. 1E); at day 21 , more pulmonary secondary septa and alveoli were observed and the alveoli were distributed more regularly and uniformly (Fig. 1G). In the hyperoxia group, at day 3, thickened pulmonary septa were observed (Fig. 1B); at day 7 , there was a decreased number of alveoli and secondary septa, and increased alveolar size in the lung tissues (Fig. 1D). At days 14 and 21, the alveolar space was significantly increased, there was further evidence of pulmonary septa thickening, the number of alveoli and secondary septa was decreased greatly, and the normal structure of alveoli had disappeared (Fig. 1F and H). At days 7, 14 and 21, the RACs of the control group were significantly increased compared with those in 




Figure 2. Alveolar development as measured using RACs. At days 7, 14, and 21 the RACs in the control group were significantly increased compared with those in the bronchopulmonary dysplasia model group. ${ }^{*} \mathrm{P}<0.05$ vs. respective control. RAC, radial alveolar count.

the BPD model group ( $\mathrm{P}<0.05$; Fig. 2). These results demonstrated that the formation of secondary septa was impaired and alveolar development was attenuated in the model group. The RACs for alveolar development were consistent with the results from the histological observations.

Localization and expression of BMP7 protein in lung tissue. BMP7 protein expression was examined (Fig. 3). Light microscopy demonstrated that, in the control group, there was little expression of BMP7 in bronchial epithelial cells (Fig. 3A-D). In the model group, BMP7 distribution was significantly increased and localized in bronchial epithelial cells in addition to pulmonary epithelial cells and interstitial cells of the pulmonary septa at day 3 (Fig. 3E). At day 7, cytoplasmic staining of BMP7 in pulmonary epithelial cells and interstitial cells was decreased (Fig. 3F). The intensity of this staining was markedly reduced in lung tissues from rats at days 14 and 21 (Fig. 3G and $\mathrm{H}$, respectively).

The protein expression of BMP7 in lung tissue was detected by semi-quantitative analysis. BMP7 protein expression was markedly increased at day 3 . Significant differences between the model group and the control group were observed $(\mathrm{P}<0.01)$. The expression of BMP7 gradually decreased over time, although it remained significantly increased compared with that of the control group at day $7(\mathrm{P}<0.01)$. However, no statistical difference was observed in the corresponding expression in the control group at days 14 and 21 ( $\mathrm{P}>0.05$; Fig. 4A).

Expression of BMP7 mRNA in lung tissue. The relative level of the BMP7 mRNA was markedly increased at day 3 in the model group. Significant differences were observed between the model and the control groups $(\mathrm{P}<0.01)$. The relative BMP7 mRNA level gradually decreased, although it remained significantly increased compared with that of the control group at day $7(\mathrm{P}<0.01)$. No statistical difference was observed in the corresponding expression level in the control group at day $14(\mathrm{P}>0.05)$. However, at day 21 , the BMP7 mRNA level in the hyperoxia group was significantly decreased compared with that of the control group $(\mathrm{P}<0.01$; Fig. 4B).
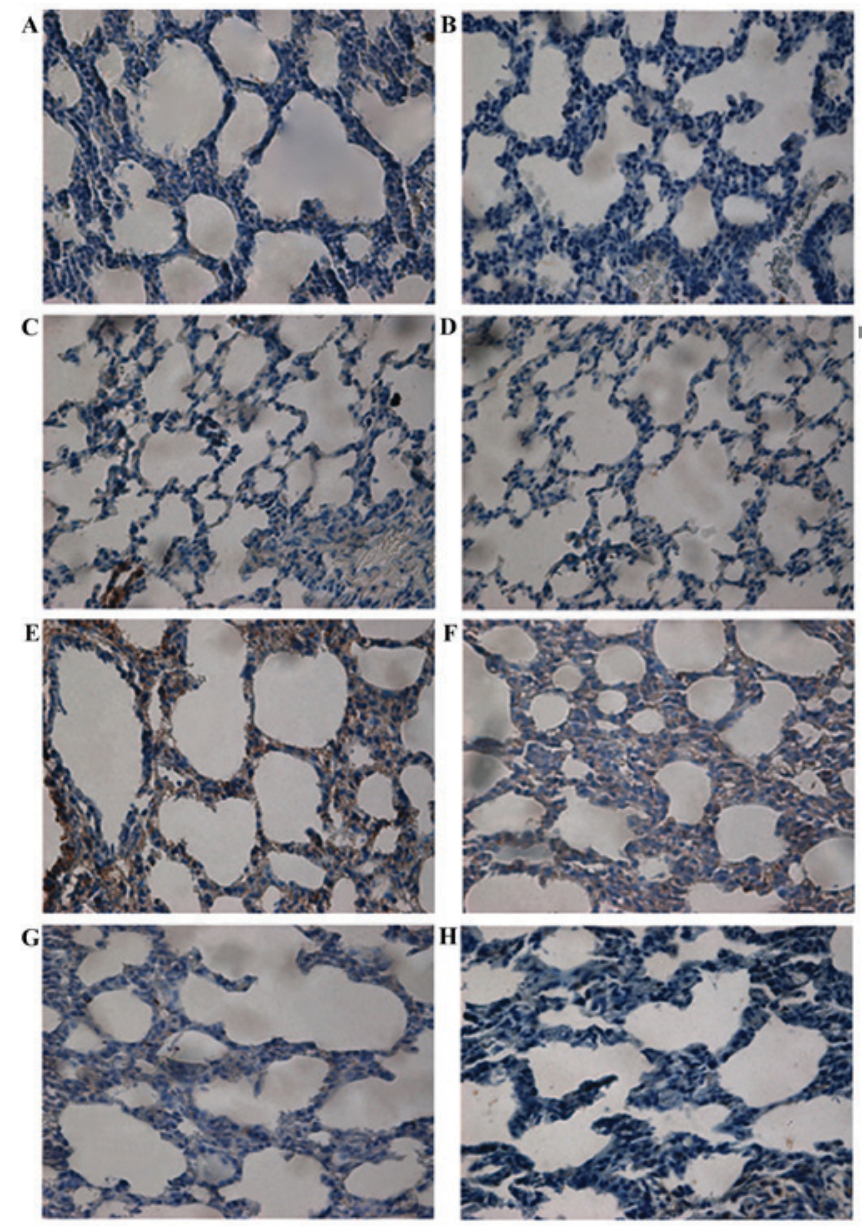

Figure 3. Representative images of immunohistochemical staining indicate the localization of BMP7 in lung tissue. Magnification, x40. (A-D) There was minimal expression of BMP7 in bronchial epithelial cells. (E) At day 3, BMP7 distribution was significantly increased and localized to bronchial and pulmonary epithelial cells, as well as the interstitial cells of the pulmonary septa. (F) At day 7, cytoplasmic BMP7 staining in pulmonary epithelial and interstitial cells was decreased. $(G)$ The intensity of this staining was markedly reduced in lung tissues from rats at days 14 and $21(\mathrm{H})$. BMP, bone morphogenetic protein.

Effect of BMP7 on LF cell proliferation of newborn rats. The cells were treated with different concentrations of BMP7 $(0,5,10$ and $50 \mathrm{ng} / \mathrm{ml})$ for different lengths of time $(12,24$ and 48 h). As presented in Fig. 5, the MTT assay demonstrated that the proliferation of LF cells was significantly inhibited. As the concentration of BMP7 increased, the cell proliferation rate decreased, which may suggest that the inhibitory effect of BMP7 on LF cell proliferation is dose-dependent. LF cells proliferated at different concentrations of BMP7 over time; however, the cell proliferation rate decreased as the concentration of BMP7 increased, which may suggest that the inhibitory effect of BMP7 on LF cell proliferation is time-dependent.

Effect of BMP7 on the cell cycle distribution of LF cells. The cell cycle distribution of LF cells was analyzed following treatment with $50 \mathrm{ng} / \mathrm{ml} \mathrm{BMP7}$ for different durations. The percentage of $L F$ cells in the $G_{1}$ phase increased over time. The percentage of LF cells in the $G_{1}$ phase was markedly increased following treatment with $50 \mathrm{ng} / \mathrm{ml} \mathrm{BMP7}$ for $12 \mathrm{~h}$. 
$\mathbf{A}$

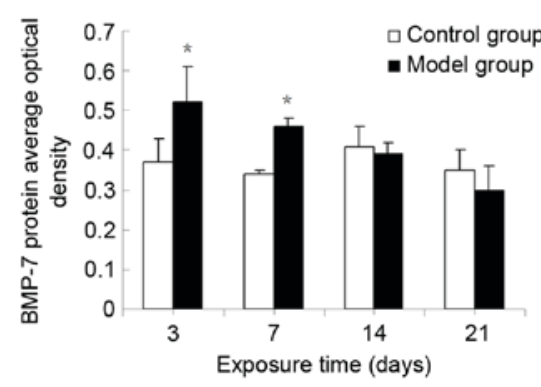

B

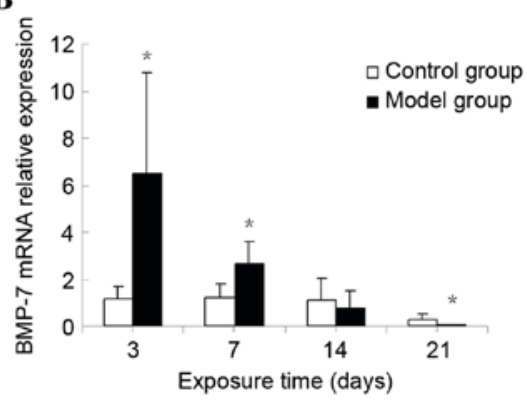

Figure 4. The protein and mRNA expression levels of BMP7 in lung tissue. (A) Immunohistochemical analysis was performed to identify alterations in the expression of BMP7 in lung tissue. The protein expression of BMP7 exhibited a gradual decrease over time. Average optical density of BMP7 protein level semi-quantitative data \pm standard deviation. ${ }^{*} \mathrm{P}<0.01$ vs. respective control. (B) The reverse transcription-quantitative polymerase chain reaction was used to analyze the relative mRNA levels of BMP-7 in lung tissue. The expression of BMP7 mRNA gradually decreased over time. Data are presented as the relative mRNA level \pm standard deviation. ${ }^{*} \mathrm{P}<0.01$ vs. respective control. BMP, bone morphogenetic protein.



Figure 5. Proliferation of LF cells, measured by MTT assay. The results revealed that the effect of BMP7 on LF cells was dose- and time-dependent. LF, lung fibroblast; BMP, bone morphogenetic protein; OD, optical density.

Significant differences between the BMP7 group and the control group were observed $(\mathrm{P}<0.05)$. As the time of treatment with BMP7 increased, the percentage of LF cells in the $G_{1}$ phase gradually increased and remained significantly increased compared with the control group at 24 and $48 \mathrm{~h}$ $(\mathrm{P}<0.05)$. In addition, significant differences between the 12 and $24 \mathrm{~h}$ groups, and the 24 and $48 \mathrm{~h}$ groups, were observed $(\mathrm{P}<0.05$; Fig. 6A).

Following treatment with BMP7 at different concentrations for $24 \mathrm{~h}$, the cell cycle distribution of LF cells was also analyzed by FCM using PI staining. The percentage of LF cells in the $\mathrm{G}_{1}$ phase increased when the concentration of BMP7 increased. Following treatment with BMP7 at concentrations of 10 and $50 \mathrm{ng} / \mathrm{ml}$, the percentages of cells in the $\mathrm{G}_{1}$ phase gradually increased, and were significantly increased compared with that of the control group $(0 \mathrm{ng} / \mathrm{ml} ; \mathrm{P}<0.05)$. Additionally, significant differences between the 5 and $10 \mathrm{ng} / \mathrm{ml}$ groups, and between the 10 and $50 \mathrm{ng} / \mathrm{ml}$ group, were observed $(\mathrm{P}<0.05$; Fig. 6B).

\section{Discussion}

With the use of pulmonary surfactants and gentle ventilation strategies, premature neonates with BPD more commonly present with milder pathological alterations, demonstrating decreased fibrosis and more lung vascular and alveolar hypoplasia (6). However, BPD with pulmonary fibrosis and alveolar hypoplasia pathological changes may be observed today. Previous studies on TGF- $\beta$ cytokines primarily focused on the activity of stimulating fibroblast proliferation $(29,30)$. However, the mechanism of BMP7 in neonates with BPD is little studied and the dynamic alterations in BMP7 expression have not been studied in BPD. Therefore, the present study was undertaken to examine the possible mechanisms underlying the pathological alterations in neonates with BPD, and to identify the function of BMP7 in neonatal LFs.

The present study was the first, to the best of the authors' knowledge, to demonstrate the dynamic expression of BMP7 in neonates with BPD. It was observed that the expression of BMP7 decreased in an in vivo model, suggesting that BMP may serve an important role in the inhibition of LF proliferation in the early stages of abnormal alveolar development. In addition, it was identified that LFs may be inhibited by BMP7, and that this effect has dose-dependent and time-dependent characteristics, suggesting that abnormal alveolar development may be postponed or prevented by directly inhibiting LF proliferation via BMP7.

Previous studies have used a hyperoxia-induced model to study BPD $(26,31)$. The present study provided novel evidence that BMP7 may be a protective cytokine, preventing abnormal alveolar development in neonates with BPD. In this model, the pathological alterations included pneumonedema and inflammation at an early stage and abnormal alveolar and vascular development at a later period; these results were consistent with a previous study (7). It was identified that when the expression of BMP7 decreased there were consistent alterations in abnormal alveolar development, suggesting that BMP7 may be a protective cytokine in the prevention of abnormal alveolar development.

BMP7 has been demonstrated to be important during the control of a number of important steps of embryogenesis, and the regulation of growth, proliferation, differentiation and apoptosis (32-34). The present study demonstrated that the expression of BMP7 was altered in neonates with BPD. Using immunohistochemistry, it was observed that hyperoxic exposure markedly stimulated the expression of BMP7 protein. However, as the hyperoxic exposure continued, the expression of BMP7 was downregulated, as confirmed by RT-qPCR analysis. Ohnuma-Koyama et al (24) identified that the expression of BMP7 was continuously decreased in 
A
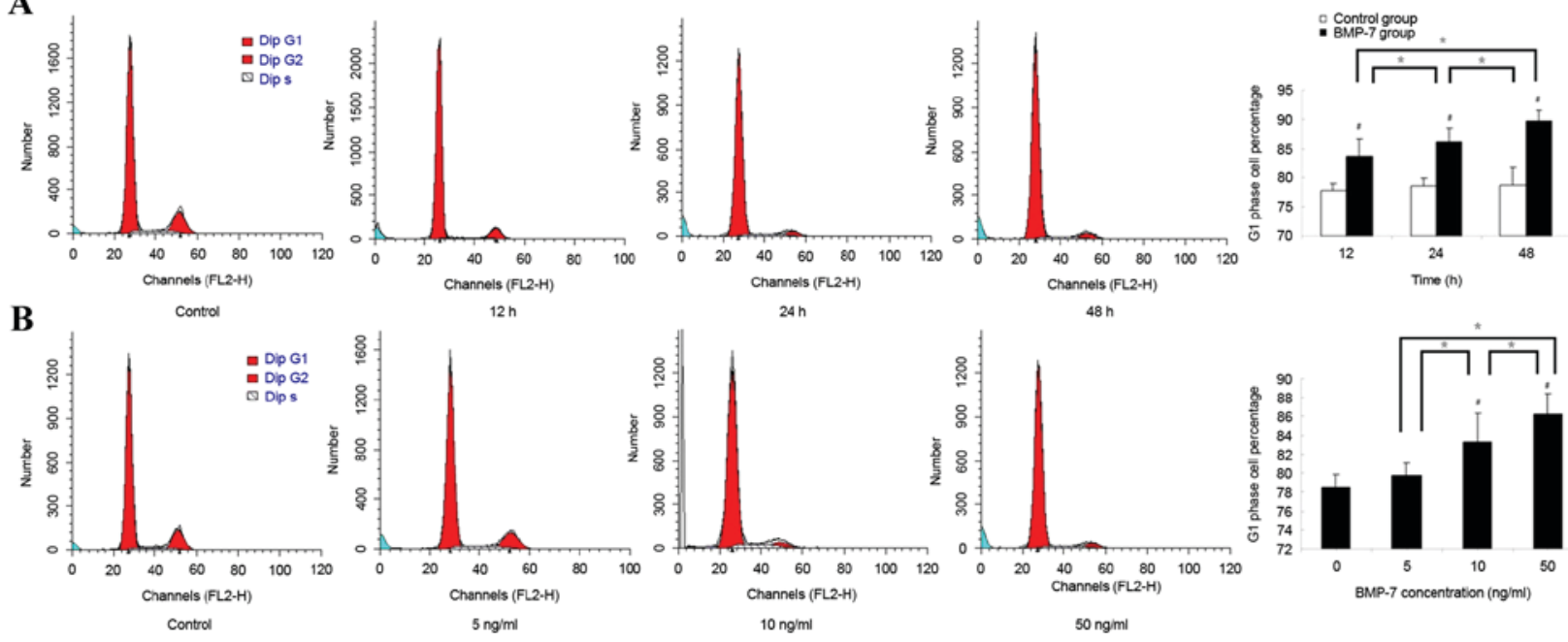

Figure 6. Cell cycle distribution of LF cells, analyzed by flow cytometry. (A) Cells were incubated with $50 \mathrm{ng} / \mathrm{ml}$ BMP7 for different durations. The cell cycle was arrested at $\mathrm{G}_{1}$ phase as the time progressed. Data are the mean \pm standard deviation. (B) Cells were incubated with BMP7 (0, 5,10 or $\left.50 \mathrm{mg} / \mathrm{ml}\right)$ for $24 \mathrm{~h}$. The cell cycle was arrested at the $\mathrm{G}_{1}$ phase as the concentration of BMP7 increased. Data are presented as the mean \pm standard deviation. ${ }^{\#} \mathrm{P}<0.05$ vs. the control group; ${ }^{*} \mathrm{P}<0.05$ vs. different time-points. LF, lung fibroblast; BMP, bone morphogenetic protein.

DDAC-induced pulmonary fibrosis. Treatment with BMP7 may inhibit and decreased silica-induced pulmonary fibrosis in rats (35). Restoration of the expression of BMP7 and a BMP target gene may prevent or hinder the progression of fibrosis in silica-induced pulmonary fibrosis (36). These previous results are consistent with the effects of BMP-7 in experimental models of kidney and liver fibrosis $(37,38)$.

In addition, the present study demonstrated that prolonged hyperoxic exposure decreased BMP7 expression. In normal lung tissue, the expression of BMP7 was stable from beginning to end, although the expression was decreased by hyperoxic exposure. This alteration in the expression of BMP7 is paralleled by prolonged hyperoxic exposure. The expression in the BPD model group on day 14 was decreased compared with the control group, and was significantly lower on day 21 . In addition, these alterations were more marked at the gene level. The results of the present study demonstrated that the expression of BMP7 was inhibited by hyperoxic exposure at the gene level in neonates with BPD, suggesting that BMP7 possibly served an essential function in the maintenance of the normal structure of lung tissue. Secondly, hyperoxic exposure stimulated BMP7 expression in order to inhibit fibroblast proliferation, preventing abnormal alveolar development; however, with continuous hyperoxic exposure the effects of the promotive cytokines are enhanced, and endogenous BMP7 expression is suppressed, resulting in fibroblast proliferation and abnormal alveolar development (39).

In order to confirm that BMP7 may be a protective cytokine in the prevention of abnormal alveolar development, the condition of LF proliferation was assayed in vitro by MTT assay. The results demonstrated that the LF cell proliferation rate decreased with the increase in BMP7 concentration. With increased time and concentration, the LF cell proliferation rate demonstrated a decreasing trend. These results suggested that BMP7 may inhibit neonatal LF proliferation in vitro. A recent study demonstrated that covalent grafting of the BMP7 peptide onto the surface of cobalt-chrome revealed the antifibrotic activity of the BMP7 peptide, and its capacity to reduce fibroblast adhesion and proliferation (40). In addition, the administration of BMP7 induced the differentiation, and inhibited the proliferation, of podocytes (41).

An additional study demonstrated that BMP7 inhibited cell proliferation in the subventricular zone through quantitative inhibition of mitogenesis (42). Miyazaki et al (43) confirmed that BMP7 caused $\mathrm{G}_{1}$ cell cycle arrest in androgen-insensitive prostate carcinoma cells. The effect of BMP7 on the LF cell cycle was assessed in the present study by FCM. The experiments demonstrated that the percentage of LF cells in the $\mathrm{G}_{1}$ phase increased as the concentration of BMP7 increased. Under the same concentration of BMP7, the percentage of LF cells in the $G_{1}$ phase was higher and increased with time. These trends were consistent with the results of the MTT assay, and the results suggested that BMP7 caused cell cycle arrest in the $\mathrm{G}_{1}$ phase. BMP7 may enhance the $\mathrm{G}_{1} / \mathrm{S}$ checkpoint activities and weaken the $\mathrm{G}_{2} / \mathrm{M}$ checkpoint activities, causing more $L F$ cells to remain at the $G_{1}$ stage, and thus perform a function in preventing LF proliferation. Therefore, there is evidence that the proliferation of LFs may be inhibited by BMP7 in vivo.

A preliminary study provided certain clues that BMP7 may inhibit LF proliferation (33). During pulmonary fibrosis, BMP7 signaling decreased and TGF- $\beta$ signaling increased, which suggested that the balance between BMP7 and TGF- $\beta$ signaling activities in the lung is of importance during lung injury and repair, and is the notable mechanism in pulmonary fibrosis (37). Whether the abnormal alveolar development in neonatal rats with BPD is via suppression of BMP7 signaling activities, resulting in a BMP7/TGF- $\beta$ signaling imbalance, requires further study.

In conclusion, the results of the present study demonstrated that BMP7 may be involved in the occurrence and development of BPD. The data demonstrated that BMP7 
expression decreased in the BPD neonatal rat model, and the alterations were inverse to the severity of the abnormal alveolar development. In vitro experiments confirmed that BMP7 may regulate the cell cycle of neonatal LFs and possesses the effect of inhibiting LF proliferation. Therefore, the present study suggested that the severity of the abnormal alveolar development may be associated with the decreased expression of BMP7, and that BMP7 may regulate LF proliferation, at least in part due to regulation of the LF cell cycle, in order to resist abnormal alveolar development. However, the specific mechanisms underlying these findings remain to be elucidated in a future study.

\section{Acknowledgements}

The present study was supported by grants from the Natural Science Foundation of China (grant nos. 30872781 and 81170605).

\section{References}

1. Bhandari A and Bhandari V: Pitfalls, problems, and progress in bronchopulmonary dysplasia. Pediatrics 123: 1562-1573, 2009.

2. Trembath A and Laughon MM: Predictors of bronchopulmonary dysplasia. Clin Perinatol 39: 585-601, 2012.

3. Stoll BJ, Hansen NI, Bell EF, Shankaran S, Laptook AR, Walsh MC, Hale EC, Newman NS, Schibler K, Carlo WA, et al: Neonatal outcomes of extremely preterm infants from the NICHD Neonatal Research Network. Pediatrics 126: 443-456, 2010.

4. Özdemir ÖM, Gözkeser E, Bir F and Yenisey Ç: The effects of resveratrol on hyperoxia-induced lung injury in neonatal rats. Pediatr Neonatol 55: 352-357, 2014.

5. Gien J and Kinsella JP: Pathogenesis and treatment of bronchopulmonary dysplasia. Curr Opin Pediatr 23: 305-313, 2011.

6. Jobe AH and Bancalari E: Bronchopulmonary dysplasia. Am J Respir Crit Care Med 163: 1723-1729, 2001.

7. Thébaud B and Abman SH: Bronchopulmonary dysplasia: Where have all the vessels gone? Roles of angiogenic growth factors in chronic lung disease. Am J Respir Crit Care Med 175: 978-985, 2007

8. Husain AN, Siddiqui NH and Stocker JT: Pathology of arrested acinar development in postsurfactant bronchopulmonary dysplasia. Hum Pathol 29: 710-717, 1998.

9. Dasgupta C, Sakurai R, Wang Y, Guo P, Ambalavanan N, Torday JS and Rehan VK: Hyperoxia-induced neonatal rat lung injury involves activation of TGF- $\{$ beta $\}$ and Wnt signaling and is protected by rosiglitazone. Am J Physiol Lung Cell Mol Physiol 296: L1031-L1041, 2009.

10. Boon MR, van der Horst G, van der Pluijm G, Tamsma JT, Smit JW and Rensen PC: Bone morphogenetic protein 7: A broad-spectrum growth factor with multiple target therapeutic potency. Cytokine Growth Factor Rev 22: 221-229, 2011.

11. Ali IH and Brazil DP: Bone morphogenetic proteins and their antagonists: Current and emerging clinical uses. Br J Pharmacol 171: 3620-3632, 2014.

12. Bragdon B, Moseychuk O, Saldanha S, King D, Julian J and Nohe A: Bone morphogenetic proteins: A critical review. Cell Signal 23: 609-620, 2011.

13. Szabò H, Fiorino G, Spinelli A, Rovida S, Repici A, Malesci AC and Danese S: Review article: Anti-fibrotic agents for the treatment of Crohn's disease-lessons learnt from other diseases. Aliment Pharmacol Ther 31: 189-201, 2010.

14. Djamali A and Samaniego M: Fibrogenesis in kidney transplantation: Potential targets for prevention and therapy. Transplantation 88: 1149-1156, 2009.

15. Yanagita M: Inhibitors/antagonists of TGF- $\beta$ system in kidney fibrosis. Nephrol Dial Transplant 27: 3686-3691, 2012.

16. Weiskirchen R, Meurer SK, Gressner OA, Herrmann J, Borkham-Kamphorst E and Gressner AM: BMP-7 as antagonist of organ fibrosis. Front Biosci (Landmark Ed) 14: 4992-5012, 2009.
17. Gressner OA, Rizk MS, Kovalenko E, Weiskirchen R and Gressner AM: Changing the pathogenetic roadmap of liver fibrosis? Where did it start; where will it go? J Gastroenterol Hepatol 23: 1024-1035, 2008.

18. Weiskirchen R and Meurer SK: BMP-7 counteracting TGF-beta1 activities in organ fibrosis. Front Biosci (Landmark Ed) 18: 1407-1434, 2013.

19. Myllärniemi M, Lindholm $P$, Ryynänen $M J$, Kliment $C R$, Salmenkivi K, Keski-Oja J, Kinnula VL, Oury TD and Koli K: Gremlin-mediated decrease in bone morphogenetic protein signaling promotes pulmonary fibrosis. Am J Respir Crit Care Med 177: 321-329, 2008

20. Kinoshita K, Iimuro Y, Otogawa K, Saika S, Inagaki Y, Nakajima Y, Kawada N, Fujimoto J, Friedman SL and Ikeda K: Adenovirus-mediated expression of BMP-7 suppresses the development of liver fibrosis in rats. Gut 56: 706-714, 2007.

21. Gressner OA and Gao C: Monitoring fibrogenic progression in the liver. Clin Chim Acta 433: 111-122, 2014.

22. Miyazaki Y, Ueda H, Yokoo T, Utsunomiya Y, Kawamura T, Matsusaka T, Ichikawa I and Hosoya T: Inhibition of endogenous BMP in the glomerulus leads to mesangial matrix expansion. Biochem Biophys Res Commun 340: 681-688, 2006.

23. Morrissey J, Hruska K, Guo G, Wang S, Chen Q and Klahr S: Bone morphogenetic protein-7 improves renal fibrosis and accelerates the return of renal function. J Am Soc Nephrol 13 (Suppl 1): S14-S21, 2002.

24. Ohnuma-Koyama A, Yoshida T, Tajima-Horiuchi H, Takahashi N, Yamaguchi S, Ohtsuka R, Takeuchi-Kashimoto Y, Kuwahara M, Takeda M, Nakashima $\mathrm{N}$ and Harada T: Didecyldimethylammonium chloride induces pulmonary fibrosis in association with TGF- $\beta$ signaling in mice. Exp Toxicol Pathol 65: 1003-1009, 2013.

25. Izumi N, Mizuguchi S, Inagaki Y, Saika S, Kawada N, Nakajima Y, Inoue K, Suehiro S, Friedman SL and Ikeda K: BMP-7 opposes TGF-beta1-mediated collagen induction in mouse pulmonary myofibroblasts through Id2. Am J Physiol Lung Cell Mol Physiol 290: L120-L126, 2006.

26. Yang H, Fu J, Xue X, Yao L, Qiao L, Hou A, Jin L and Xing Y: Epithelial-mesenchymal transitions in bronchopulmonary dysplasia of newborn rats. Pediatr Pulmonol 49: 1112-1123, 2014.

27. Livak KJ and Schmittgen TD: Analysis of relative gene expression data using real-time quantitative PCR and the 2(-Delta Delta C(T)) method. Methods 25: 402-408, 2001.

28. Kelleher MD, Naureckas ET, Solway J and Hershenson MB: In vivo hyperoxic exposure increases cultured lung fibroblast proliferation and c-Ha-ms expression. Am J Respir Cell Mol Biol 12: 19-26, 1995.

29. Nakanishi H, Sugiura T, Streisand JB, Lonning SM and Roberts JD Jr: TGF-beta-neutralizing antibodies improve pulmonary alveologenesis and vasculogenesis in the injured newborn lung. Am J Physiol Lung Cell Mol Physiol 293: L151-L161, 2007.

30. Kumarasamy A, Schmitt I, Nave AH, Reiss I, van der Horst I, Dony E, Roberts JD Jr, de Krijger RR, Tibboel D, Seeger W, et al: Lysyl oxidase activity is dysregulated during impaired alveolarization of mouse and human lungs. Am J Respir Crit Care Med 180: 1239-1252, 2009.

31. Ahn SY, Chang YS, Sung DK, Yoo HS, Sung SI, Choi SJ and Park WS: Cell type-dependent variation in paracrine potency determines therapeutic efficacy against neonatal hyperoxic lung injury. Cytotherapy 17: 1025-1035, 2015.

32. Sieber C, Kopf J, Hiepen C and Knaus P: Recent advances in BMP receptor signaling. Cytokine Growth Factor Rev 20: 343-355, 2009.

33. Danesh SM, Villasenor A, Chong D, Soukup C and Cleaver O: $\mathrm{BMP}$ and $\mathrm{BMP}$ receptor expression during murine organogenesis. Gene Expr Patterns 9: 255-265, 2009.

34. Kazama I, Mahoney Z, Miner JH, Graf D, Economides AN and Kreidberg JA: Podocyte-derived BMP7 is critical for nephron development. J Am Soc Nephrol 19: 2181-2191, 2008.

35. Yang G, Zhu Z, Wang Y, Gao A, Niu P and Tian L: Bone morphogenetic protein-7 inhibits silica-induced pulmonary fibrosis in rats. Toxicol Lett 220: 103-108, 2013.

36. Leppäranta O, Tikkanen JM, Bespalov MM, Koli K and Myllärniemi M: Bone morphogenetic protein-inducer tilorone identified by high-throughput screening is antifibrotic in vivo. Am J Respir Cell Mol Biol 48: 448-455, 2013.

37. Yang T, Chen SL, Lu XJ, Shen CY, Liu Y and Chen YP: Bone morphogenetic protein 7 suppresses the progression of hepatic fibrosis and regulates the expression of gremlin and transforming growth factor $\beta 1$. Mol Med Rep 6: 246-252, 2012. 
38. Wang S, de Caestecker M, Kopp J, Mitu G, Lapage J and Hirschberg R: Renal bone morphogenetic protein-7 protects against diabetic nephropathy. J Am Soc Nephrol 17: 2504-2512, 2006.

39. Alejandre-Alcázar MA, Kwapiszewska G, Reiss I, Amarie OV Marsh LM, Sevilla-Pérez J, Wygrecka M, Eul B, Köbrich S, Hesse M, et al: Hyperoxia modulates TGF-beta/BMP signaling in a mouse model of bronchopulmonary dysplasia. Am J Physiol Lung Cell Mol Physiol 292: L537-L549, 2007.

40. Tan HC, Poh CK, Cai Y and Wang W: Anti-fibrosis effect of BMP-7 peptide functionalization on cobalt chromium alloy. J Orthop Res 31: 983-990, 2013.

41. Yamada S, Nakamura J, Asada M, Takase M, Matsusaka T, Iguchi T, Yamada R, Tanaka M, Higashi AY, Okuda T, et al: Twisted gastrulation, a BMP antagonist, exacerbates podocyte injury. PLoS One 9: e89135, 2014.
42. Douet V, Arikawa-Hirasawa E and Mercier F: Fractone-heparan sulfates mediate BMP-7 inhibition of cell proliferation in the adult subventricular zone. Neurosci Lett 528: 120-125, 2012.

43. Miyazaki $\mathrm{H}$, Watabe $\mathrm{T}$, Kitamura $\mathrm{T}$ and Miyazono K: BMP signals inhibit proliferation and in vivo tumor growth of androgen-insensitive prostate carcinoma cells. Oncogene 23: 9326-9335, 2004.

This work is licensed under a Creative Commons Attribution-NonCommercial-NoDerivatives 4.0 International (CC BY-NC-ND 4.0) License. 